\title{
El ecumenismo de los mártires
}

\author{
Martin Maier, S.J., \\ Berchmanskolleg, München, \\ Centro de Reflexión Teológica, San Salvador
}

El papa Juan Pablo II, en su Carta Apostólica Tertio Millennio Adveniente, del 10 de noviembre de 1994, habló de "la vuelta de los mártires". "Al término del segundo milenio, la Iglesia ha vuelto de nuevo a ser Iglesia de mártires. Las persecuciones de creyentes - sacerdotes, religiosos y laicos- han supuesto una gran siembra de mártires en varias partes del mundo. El testimonio ofrecido a Cristo hasta el derramamiento de la sangre se ha hecho patrimonio común de católicos, ortodoxos, anglicanos y protestantes (...) Es un testimonio que no hay que olvidar" (n. 37). Con ello, Juan Pablo II muestra un hecho indiscutible: nunca antes del siglo XX ha habido en la historia de la Iglesia tantos hombres y mujeres que han llegado a ser testigos de la fe a través de la entrega de su vida, sobre todo bajo los totalitarismos nazi y soviético y las dictaduras militares en América Latina. Por otro lado, el papa subrayó la dimensión ecuménica del martirio. Cristianos y cristianas de todas las confesiones han derramado su sangre por Cristo. Juan Pablo II llamó a eso "un patrimonio común". La fecundidad de ese patrimonio hasta ahora no ha sido tenida suficientemente en cuenta.

Sin embargo, en la perspectiva de las luchas confesionales del pasado hay que reconocer honradamente que el título de mártir ha sido usado de manera propagandística por los dos lados. Estos "mártires" se han convertido trágicamente en signos de lo que separa. Pero desde la perspectiva de Juan Pablo II, ha sido superada esa comprensión rivalizante de los mártires. Los mártires ya no separan a las confesiones, sino que las unen. 


\section{El ecumenismo en el Círculo de Kreisau}

Un ejemplo conmovedor de ese ecumenismo es la historia de la resistencia contra el nacionalsocialismo en el Círculo de Kreisau ${ }^{1}$. Helmuth James von Moltke, convencido protestante, había reunido conscientemente a católicos y protestantes para planificar el futuro de Alemania después del desastre del nacionalsocialismo y de la Segunda Guerra Mundial. Así, tras la detención de los miembros más importantes del Círculo de Kreisau, se formó en la prisión de Tegel, en Berlín, una comunidad ecuménica de destino y de oración con Helmuth James von Moltke, Eugen Gerstenmaier, Alfred Delp, S.J., y Joseph Ernst Fugger von Glött. Dicha comunidad fue apoyada por los dos pastores de la prisión, el católico Peter Buchholz y el protestante Harald Poelchau. Alfred Delp lo describió así en una carta, poco antes de la Navidad de 1944: "Para Navidad, los cuatro hemos empezado una novena en común. Esta es la Una Sancta in vinculis en oración. Cada día se celebra por Moltke una santa misa en la cripta de San Gereón, en Colonia"2.

El futuro del ecumenismo fue también un tema entre los de Kreisau. El 31 de diciembre de 1944, Alfred Delp escribió a Eugen Gerstenmaier:

Tenemos que cargar hacia adelante con el peso histórico de las Iglesias separadas, como peso y patrimonio. Eso no debe ser nunca más una vergüenza de Cristo. No creo en las utopías de unidad, como tampoco tú, pero el Cristo Único es indiviso, y donde el amor indiviso lleva a él vamos a lograr muchas cosas mejor que como lo hicieron nuestros antepasados y contemporáneos en litigio. Yo tengo también fuera de la misa el sacramento en la celda y hablo a menudo con el Señor sobre ti. Él nos consagra aquí para una nueva misión. ${ }^{3}$

En un breve texto sobre "El destino de las Iglesias", Delp formula la siguiente convicción: "Si las Iglesias vuelven a ofrecer a la humanidad la imagen de una cristiandad litigante, no tienen futuro"4.

En el juicio a los miembros del Círculo de Kreisau ante la Corte del Pueblo, el ecumenismo, en sí mismo, se convirtió en "delito". El juez ejecutor Roland Freisler acusó a Moltke de manera específica de que, siendo protestante, se había unido a los católicos y a los jesuitas. Sobre ello, Moltke escribió a su esposa Freya, poco antes de ser asesinado: “(...) y entonces tu dueño es escogido para ser atacado y condenado como protestante ante todo por su amistad con los católicos, y está frente a Freisler no como protestante, no como gran

1. Cfr. M. Maier, "Alfred Delp, S.J., mártir de una humanidad más justa", Revista Latinoamericana de Teologia, 77 (2009), pp. 101-120.

2. A. Delp, Gesammelte Schrften, vol. IV: Aus dem Gefängnis, Frankfurt, 1984, p. 60.

3. Ibid., pp. 76 y s.

4. Ibid., p. 319. 
terrateniente, no como noble, no como prusiano, no como alemán (...), sino como cristiano y nada más"s.

Después de que pronunciaron su sentencia de muerte, todavía tuvo suficiente humor para escribir sobre la agresividad de Freisler por su colaboración con los jesuitas: "Pero que muero como mártir por san Ignacio de Loyola $\rightarrow$ y eso es lo central, porque todo lo demás era secundario, en comparación- es probablemente un chiste, y ya estoy temblando frente a la ira paternal de papi, quien era tan anticatólico. Lo otro lo aprobará, ¿pero eso?"6.

En la última carta de Moltke a Delp, vuelve a decir:

(...) con eso, la verdadera ofensiva de Freisler se dirigió contra la Iglesia católica y la Iglesia evangélica, contra mí, siendo liberado de todo interés y de toda violencia, siendo un laico protestante, cuyas relaciones con los católicos eran el objeto de los ataques más fuertes. El nacionalsocialista Freisler solamente podía actuar contra mí como cristiano por antonomasia. Eso le ha forzado a estas afirmaciones extremas y claras sobre la última incompatibilidad entre el cristianismo y el nacionalsocialismo. Aunque caigamos, eso quedará como semilla fecunda para el país. ${ }^{7}$

El "ecumenismo de las catacumbas" del Círculo de Kreisau, por un lado, tuvo ciertamente un efecto catalizador para el desarrollo del ecumenismo oficial de las iglesias en Alemania y más allá en el siglo XX. Por otro lado, este "patrimonio común", en el sentido de Juan Pablo II, hasta ahora no ha sido suficientemente honrado y hecho fecundo. Y es llamativo que, en las últimas décadas, las reflexiones más importantes sobre el tema del martirio vinieron de la teología de la liberación latinoamericana. El transfondo es la persecución y la muerte violenta de centenares de miles de cristianos y cristianas comprometidos por la fe y los derechos humanos en los países de América Latina. Jon Sobrino habla de la Iglesia latinoamericana como de "una Iglesia de los mártires".

\section{El ecumenismo de los mártires en América Latina}

Las condiciones para el ecumenismo en América Latina son distintas de las existentes en Europa o en Estados Unidos. A pesar del rápido crecimiento de las iglesias evangélicas pentecostales, la mayoría de la población de América Latina sigue siendo católica. La teología y la espiritualidad de muchos evangélicos y pentecostales son decididamente apolíticos, en el sentido de que la pregunta sobre la justicia social es sustituida por una espiritualidad carismática. Pero

5. H. J. von Moltke, Im Land der Gottlosen. Tagebuch und Briefe aus der Haft 1944/45, München, 2009, p. 341.

6. Ibid., p. 333.

7. A. Delp, Gesammelte Schrften, vol. IV, óp. cit., pp. 436 y s. 
también hay ejemplos de cristianos protestantes que han sido asesinados por su compromiso por la justicia, que la misma fe exige. A título personal, quiero mencionar un ejemplo.

De 1989 a 1991, estuve en El Salvador, en el contexto de mi tesis doctoral. El 16 de noviembre de 1989 me tocó vivir el asesinato-martirio de los seis jesuitas y las dos mujeres, por su compromiso por la paz y la justicia. Con Ignacio MartínBaró, había colaborado los fines de semana en la parroquia de Jayaque. Después del asesinato de Nacho me tocó continuar junto con un grupo de religiosas el trabajo pastoral en la parroquia.

En Jayaque hay una pequeña comunidad luterana. A comienzos de 1990 , escuché que su pastor, Francisco Carrillo, había sido acusado por los militares locales de comportarse "como los católicos y los jesuitas". Así se valoró su compromiso por la justicia y los derechos humanos. Entonces, yo entré en contacto con él y le dije que eso sería una invitación al ecumenismo. Carrillo se puso muy contento y me invitó a la celebración de la confirmación de un grupo de jóvenes de su comunidad. No totalmente en conformidad con las normas romanas, acepté su invitación de dar el pan y el vino a los que recibieron por primera vez la cena del Señor. A mí me pareció que habíamos vivido una circunstancia ecuménica especial, como lo describió el Concilio Vaticano II: "La significación de la unidad prohíbe de ordinario la comunicación (communicatio in sacris). La consecución de la gracia algunas veces la recomienda" (Unitatis redintegratio, $\mathrm{n}^{\circ} 8$ ). Por mi parte, invité al pastor Carrillo a participar en la celebración de nuestra fiesta patronal. De ahí nació una gran amistad personal y ecuménica que se ha mantenido cuando yo ya no estaba permanentemente en El Salvador. Por eso me afectó profundamente cuando Francisco Carrillo y su esposa Jesús fueron asesinados a sangre fría el 4 de noviembre de 2006, después de la celebración de un culto. En las semanas anteriores, habían recibido amenazas por su trabajo por los derechos humanos. Francisco Carrillo y su esposa Jesús son, para mí, testigos del ecumenismo de los mártires, y me siento personalmente muy unido a ellos.

Ante las atrocidades sucedidas en América Latina, y ante las que siguen sucediendo, en la mayoría de los casos, el mundo reacciona solo cuando son asesinadas personalidades conocidas, como, por ejemplo, en El Salvador, monseñor Óscar Romero, el 24 de marzo de 1980; o los seis jesuitas de la Universidad Centroamericana, el 16 de noviembre de 1989. El último obispo asesinado en América Latina fue Juan Gerardi, el 26 de abril de 1998, dos días después de presentar en público un Libro Blanco, sobre las dolorosas violaciones de los derechos humanos en Guatemala, en los años de la guerra civil. Fue matado con una piedra. Dicho Libro Blanco, que contiene más de 1,400 páginas en tres volúmenes, tiene por título Recuperación de la memoria histórica. Por eso, el obispo Gerardi fue designado "mártir de la memoria de un pueblo". Estos 
mártires "conocidos" representan a muchos desconocidos. Así como en vida son voz de los que no tienen voz, también lo son en su muerte.

El gran número de mártires en América Latina es consecuencia del nuevo resurgir eclesial que tiene relación con la Segunda Asamblea del Episcopado Latinoamericano, celebrada en la ciudad colombiana de Medellín en 1968. Allí intentaron los obispos recrear en el contexto latinoamericano el acontecimiento que supuso la celebración del Concilio Vaticano II. Lo que para el Concilio significó una apertura de la Iglesia al mundo moderno se convirtió en Medellín en una apertura de la Iglesia al mundo de los pobres, lo que más tarde se formuló como "opción por los pobres". Ello supuso, para la Iglesia de América Latina, un cambio de orientación. Mientras que en los siglos posteriores a la conquista violenta — sin tener en cuenta pocas y honrosas excepciones- la Iglesia estuvo del lado de los poderosos y de los ricos, ahora había roto, en parte, dicha alianza y se había convertido en defensora de los pobres y de sus derechos. Con ello. surgió un conflicto, de manera especial, en El Salvador.

\section{Ampliación del concepto teológico del martirio}

Jon Sobrino escribe, en sus recuerdos sobre monseñor Romero, que el arzobispo le pidió reflexionar teológicamente sobre la realidad de la persecución y del martirio. Sobrino subraya que había pocos textos que iluminaran la persecución y el martirio de una manera y un modo teológico, tal y como estos se daban en El Salvador, y, de hecho, el tema del martirio aparece en la teología europea solamente de manera marginal ${ }^{8}$. Por el contrario, el martirio se ha convertido en un tema central en la teología de la liberación en América Latina, que toma como punto de partida de su quehacer la realidad histórica. Así escribe el teólogo boliviano Víctor Codina: "Mientras el tema del martirio parecía ausente de la teología moderna europea, la teología de la liberación lo ha actualizado con fuerza, como consecuencia de las persecuciones de la Iglesia en América Latina en estos últimos años"'.

Las siguientes reflexiones sobre el martirio, desde la teología de la liberación, no son explícitamente ecuménicas. Pero en cuanto "mártires del reino de Dios" y "mártires jesuánicos", los testigos de sangre de las Iglesias latinoamericanas ya no pertenecen a ninguna confesión específica, sino que son mártires cristianos, tal como Helmuth James von Moltke lo había afirmado. Se puede ir todavía más lejos. Si ser cristiano significa, en lo más profundo, entregarse por amor a los demás, lo más cristiano y lo más ecuménico que hay es el martirio por amor.

8. L. Weckel, Um des Lebens willen. Zu einer Theologie des Martyriums aus befreiungstheologischer Sicht, Mainz, 1998.

9. V. Codina, Parábolas de la mina y el lago. Teología desde la noche oscura, Salamanca, 1990, p. 178. 
Este amor, en un mundo de injusticia, tiene que traducirse en compromiso con los más pobres y excluidos. Así, es considerado mártir el que ha entregado su vida por instaurar un mundo más humano, más justo. Se trata de mártires por la humanidad en el doble sentido de la palabra: humanidad en cuanto valores humanos, pero humanidad también en el sentido de abarcar a todos los seres humanos en sus derechos y anhelos de vida. Desde esta perspectiva, el movimiento ecuménico significa llevarnos unos a otros en la construcción del Reino de Dios. La verificación de esta praxis es la persecución: "Bienaventurados los que padecen persecución por causa de la justicia, porque de ellos es el Reino de los Cielos" (Mt 5, 10).

En su reflexión teológica sobre el martirio, la teología de la liberación no parte de la definición canónico-dogmática de martirio, sino de la realidad viva de América Latina. Así describe Sobrino su enfoque sobre la teología del martirio: "Tuve que empezar a argumentar teológicamente con la realidad"10. De ello resulta que la realidad del martirio, tal y como se presenta en América Latina, no se podía captar con los conceptos teológicos y canónicos tradicionales. La realidad condujo a la teología a desarrollarse aún más y a ampliar su conceptualización y sistematización, partiendo de los acontecimientos históricos. Así lo expresa Jon Sobrino:

Esta novedad en la razón para asesinar cristianos y el elevadísimo número de ellos ha obligado a repensar la definición del martirio, pues de otro modo se caería en la paradójica situación de que muchos cristianos son dados (jsic!) muerte violenta, pero no pueden ser llamados mártires. Y sea cual fuere la definición oficial de martirio, el sentido común y el sentido de la fe dicen que las cosas no pueden ser así. ${ }^{11}$

Una buena presentación del concepto tradicional de martirio se encuentra en un artículo de Otto Semmelroth, en la enciclopedia teológica Sacramentum mundi ${ }^{12}$. Semmelroth distingue el elemento material (la muerte violenta que se sufre) y el elemento formal (por amor y a causa de una vida como la de Jesús). Que una muerte sea reconocida por la Iglesia como martirio presupone que se sufre con consentimiento libre, y que no se trata ni de una caída en una lucha armada ni de un ser matado inconscientemente. El mártir da testimonio del significado y de la verdad de su fe. Un momento esencial es, pues, el odium fidei, el odio contra la fe cristiana. El martirio presupone una renuncia personal y libre

10. J. Sobrino, "Mi recuerdo de monseñor Romero", Revista Latinoamericana de Teologia, 16 (1989), p. 25.

11. J. Sobrino, Jesucristo liberador. Lectura histórica-teológica de Jesús de Nazaret, San Salvador, 1991, p. 442.

12. O. Semmelroth, "Martirio", en Sacramentum mundi, IV, Barcelona, 1984, pp. 455-460. 
de la vida. Se trata de la mayor plenitud del amor, expresada en la unión entre amor a Dios y al prójimo. El martirio significa "entrega amorosa y creyente al Tú divino". El martirio es un testimonio eficaz para los demás. Expresado en forma cristológica, es una conformación con la vida de Cristo y una "participación por la gracia en la muerte de Cristo, pero también en la eficacia de la misma". De modo que también se reconoce en el martirio una cualidad soteriológica.

En perspectiva histórica, el concepto del martirio es un concepto análogo, que se ha transformado a lo largo de la historia y se ha acomodado a nuevas realidades. Un ejemplo relativamente reciente de ello es la Constitución Apostólica de Juan Pablo II Divinus Perfectionis Magister, del 25 de enero de 1983, en la que se regula de nuevo el proceso eclesial de canonización. En ella se menciona, como criterio del reconocimiento de una muerte violenta sufrida por la Iglesia en cuanto muerte martirial, también incluso "in aerumnis carceris", es decir, "en la tribulación de la cárcel". Con ello se alcanza la posibilidad de reconocer como mártires oficiales de la Iglesia a personas que murieron a consecuencia de su encarcelamiento o de los malos tratos recibidos en los campos de concentración nazis. La Iglesia ha cambiado y ampliado, pues, su comprensión del martirio.

Karl Rahner es uno de los pocos teólogos europeos que, desde el punto de vista teológico, se ha ocupado de manera intensa del tema del martirio. Justo antes de su muerte, abogaba por una ampliación del concepto clásico en un artículo suyo en la revista Concilium, titulado "Dimensiones del martirio". Su punto de partida es la pregunta de si se puede aplicar también el concepto de martirio a una persona que haya muerto en lucha activa. Afirma que "la muerte soportada pasivamente por Jesús fue la consecuencia de una lucha de Jesús contra los dirigentes políticos y religiosos de su tiempo". La muerte de Jesús no puede ser vista sin relación con su vida, la cual comprende también una lucha contra la opresión y explotación social y religiosa. Jesús entró en conflicto con los poderosos de su tiempo por haber anunciado el Reino de Dios y por su praxis correspondiente. En este orden, Rahner dirige su mirada - lo cual no deja de ser interesante- hacia El Salvador y se pregunta: "Pero ¿por qué no habría de ser mártir un monseñor Romero, por ejemplo, caído en la lucha por la justicia en la sociedad, en una lucha que él hizo desde sus más profundas convicciones cristianas?"'13.

El fenómeno del martirio en América Latina presenta igualmente un reto a la comprensión del martirio en el derecho canónico. Los procesos de beatificación oficiales de la Iglesia tienen un desarrollo lento y puntilloso. Sin embargo, en América Latina, muchas personas que han sido asesinadas como cristianos son reconocidas por sus comunidades espontáneamente como mártires. Eso es lo que dijo el arzobispo Romero en relación con los dos primeros sacerdotes asesinados

13. K. Rahner, "Dimensiones del martirio", Concilium, 19 (1983), p. 323. 
en El Salvador, Rutilio Grande y Alfonso Navarro: para él son "dos mártires auténticos".

Para mí, que son verdaderos mártires, en el sentido popular, naturalmente. Yo no me estoy metiendo en el sentido canónico, donde ser mártir supone un proceso de la suprema autoridad de la Iglesia que lo proclame mártir ante la Iglesia universal. Yo respeto esa ley y jamás diré que nuestros sacerdotes asesinados han sido mártires canonizados. Pero sí son mártires en el sentido popular, son hombres que han predicado precisamente esa incardinación con la pobreza. (Homilía del 23 de septiembre de 1979.)

\section{El Dios de la vida y los ídolos de la muerte}

El martirio en América Latina se inscribe en el conflicto social y político que dominó y aún domina en la mayoría de los países del subcontinente. La época de las dictaduras militares ya se ha superado; sin embargo, los problemas que han conducido a la represión y a la guerra civil no han desaparecido todavía. La realidad del martirio en América Latina refleja la conflictiva y dialéctica estructura de la realidad.

Este carácter dialéctico y conflictivo de la realidad se expresa en la teología de la liberación como oposición entre el Dios de la vida y los ídolos de muerte ${ }^{14}$. El arzobispo Óscar Romero de nuevo trajo a colación a los ídolos, considerándolos como una realidad enteramente actual: la idolatría de la riqueza, del poder, de la ideología de la seguridad nacional, que son absolutizados y exigen víctimas. Esto lo expresó en una de sus homilías: "Yo denuncio, sobre todo, la absolutización de la riqueza. Este es el gran mal de El Salvador: la riqueza, la propiedad privada como un absoluto intocable, y jay del que toque ese alambre de alta tensión, se quema!" (Homilía del 12 de agosto de 1979).

La conflictividad de la fe cristiana está en relación con la conflictividad de la realidad. En esta se da una activa existencia de ídolos, que Sobrino pone en relación con lo que denomina antirreino. Los mártires "expresan que existen víctimas y victimarios, justicia e injusticia, gracia y pecado. Expresan que existe el Reino de Dios y el antirreino, el Dios de vida, Abba, y los dioses de la muerte. Expresan que Jesús es verdad y vida, y que el Maligno es mentiroso y asesino"15.

En América Latina el martirio surge como consecuencia de la crítica profética, que la Iglesia y la teología han ejercido en relación con dichos dioses. Mientras la Iglesia se limite a la beneficencia caritativa, no será molesta ni

14. AA. VV., La lucha de los dioses. Los ídolos de la opresión y la búsqueda del Dios liberador, San José, 1980.

15. J. Sobrino, "Los mártires jesuánicos en el Tercer Mundo", Revista Latinoamericana de Teología, 48 (1999), p. 249. 
amenazante para nadie. Sin embargo, cuando comienza a preguntarse por las causas de la pobreza y de la injusticia, pronto surgirá la persecución a la Iglesia. Esta cuestión la expresó el arzobispo Hélder Câmara con unas conocidas palabras: "Si doy pan a los pobres, me llaman santo. Pero si pregunto por qué los pobres no tienen nada para comer, entonces me tachan de comunista"16.

Además, hay que tener en cuenta que no se persigue a la Iglesia como institución, sino solo a aquella parte de ella que ha tomado en serio la opción por los pobres. Con ello se da una ruptura en la misma Iglesia. Esto se hizo visible en la época de Óscar Romero como arzobispo de San Salvador, cuando se dio una ruptura, para él tan dolorosa, en la conferencia episcopal. La ruptura social condujo a una ruptura al interior de la propia Iglesia.

En América Latina hay un martirio que no procede de un "odium fidei", sino de un "odium iustitiae". Esto se expresa también en el hecho de que, por regla general, hay cristianos que matan a otros cristianos. De ahí que, tras el asesinato de sus compañeros jesuitas, a Jon Sobrino, en Tailandia, le hicieron la sorprendente pregunta: "¿Hay realmente católicos en su país que matan a sacerdotes?". Puesto que los mártires son asesinados por su opción por la justicia y la dignidad humana de los pobres, el martirio en América Latina está en relación fundamental con la opción por los pobres.

Igualmente, la memoria de los mártires en América Latina se inscribe dentro del carácter conflictivo de la realidad. Esta memoria es un ejemplo concreto de lo que Johann Baptist Metz denominó "la memoria peligrosa". A comienzos de los años ochenta, tras el asesinato del arzobispo Romero, era peligroso para los pobres de El Salvador tener colgada en sus champas una simple foto de él. En no pocos casos eso bastaba para que, cuando la champa era registrada por los militares, una foto de Romero fuera motivo para considerar a alguien "subversivo" y para hacerle "desaparecer".

\section{Teología del martirio}

Tras este acceso más fenomenológico a la realidad del martirio en Latinoamérica, y siguiendo el ejemplo de Jon Sobrino, se puede esbozar cómo los mártires iluminan también los contenidos centrales de la teología. Los acentos se ponen en la cristología, la eclesiología y la soteriología. La perspectiva sigue siendo ecuménica porque estos contenidos marcan tanto una teología católica como una teología protestante.

16. Citado por L. Kaufmann, Damit wir morgen Christ sein können. Vorläufer im Glauben, Freiburg, 1984, p. 99. 


\subsection{Punto de vista cristológico: los mártires jesuánicos}

Sobrino denomina a los mártires de América Latina "mártires jesuánicos", porque han sido asesinados por haber seguido a Jesús y por las mismas razones por las que a él le quitaron la vida. De ahí que pueda decir: "Los mártires son, histórica y existencialmente, la mejor mistagogía para la cristología" ${ }^{17}$. Para Sobrino, los mártires de América Latina presentan el rostro jesuánico del cristianismo y le proporcionan credibilidad. La praxis de Jesús se ha convertido en el punto de referencia fundamental de la comprensión latinoamericana del martirio.

Los mártires son testigos de la causa de Jesús: el reinado de Dios en favor de los pobres. Anunciar en la práctica el reinado de Dios significa identificarse con los pobres, con los que no tienen bienes, con los que están privados de sus derechos. Ello lleva al profeta y al mediador del reinado de Dios a la peligrosa zona de los poderosos. Ya en el Evangelio se dice que la persecución es un signo de que las personas siguen realmente a Jesús en la Iglesia. De manera que la disposición a ofrecer la propia vida es una condición del seguimiento de Jesús:

Mártir es no solo ni principalmente el que muere por Cristo, sino el que muere como Jesús; mártir es no solo ni principalmente el que muere por causa de Cristo, sino el que muere por la causa de Jesús. Martirio es, pues, no solo muerte por fidelidad a alguna exigencia de Cristo, que hipotéticamente pudiera incluso haber sido arbitraria, sino reproducción fiel de la muerte de Jesús. $^{18}$

Si se comprende el martirio en este sentido de participación en la muerte de Jesús, se iluminan entonces recíprocamente la muerte de los mártires y la cruz de Jesús:

Digamos también que la cruz de Jesús remite a las cruces existentes, pero que estas, a su vez, remiten a la de Jesús, y que son, históricamente, la gran hermenéutica para comprender por qué matan a Jesús, y, teológicamente, expresan en sí mismas la pregunta inacallable del misterio de por qué muere Jesús. ${ }^{19}$

\subsection{Punto de vista eclesiológico: el martirio como signo de la verdadera Iglesia}

En América Latina el martirio posee también una dimensión eclesiológica. Así, el arzobispo Romero comprendió la persecución como uno de los signos de la Iglesia: "La persecución es una nota característica de la autenticidad de la Iglesia. Una Iglesia que no sufre persecución, sino que está disfrutando de los

17. J. Sobrino, "Los mártires jesuánicos", óp. cit., p. 250.

18. J. Sobrino, Jesucristo liberador, óp. cit., p. 444.

19. Ibid., p. 310. 
privilegios y el apoyo de las cosas de la tierra, jtenga miedo!, no es la verdadera Iglesia de Jesucristo" (Homilía del 11 de marzo de 1979). Romero vio en la persecución de la Iglesia un signo por el cual ella realiza fielmente su misión. De ahí que pudiera pronunciar estas sorprendentes palabras:

Me alegro, hermanos, de que nuestra Iglesia sea perseguida precisamente por su opción por los pobres y por tratar de encarnarse en el interés de los pobres, y decir a todo el pueblo, gobernantes, ricos y poderosos: si no se hacen pobres, si no se interesan por la pobreza de nuestro pueblo como si fuera su propia familia, no podrán salvar a la sociedad. (Homilía del 15 de julio de 1979.)

La Iglesia en América Latina se enfrentó también con la realidad de un "martirio colectivo". Con ello se quiere hacer referencia a las masacres de El Salvador y Guatemala, en las que a veces cientos de personas, la mayoría de ellas mujeres y niños, o multitudes de pobres, fueron asesinados. No pocas veces estas masacres guardaban relación con el hecho de que se hiciera visible en las distintas comunidades una pastoral liberadora, caracterizada por el espíritu de los documentos de Medellín. En esos casos, falta el aspecto de la entrega libre de la vida y también, frecuentemente, las virtudes que son necesarias para la canonización. Sin embargo, la Iglesia debe encontrar una conexión de carácter teológico con esta realidad. En este sentido, Romero acuñó el término "pueblo crucificado", que se convirtió en concepto central para la teología de Ignacio Ellacuría y Jon Sobrino ${ }^{20}$. Sobrino esboza el concepto de martirio por medio de un significado análogo: asesinados en masa, de manera anónima y sin culpa, a los que identifica con el siervo de Yahveh del profeta Isaías, y a los que denomina como el "pueblo crucificado" y el pueblo martirial ${ }^{21}$.

\subsection{Punto de vista soteriológico: el sentido salvífico del martirio}

En la Biblia ya se habla, en Isaías, en el cuarto canto del siervo, del sentido salvífico del padecimiento de una muerte violenta por los demás. En dicho texto, se habla del siervo sufriente, que llega a justificar a muchos y a ser luz para los pueblos. En el Nuevo Testamento se considera en sentido salvífico una frase de la carta del Apóstol Pablo a los colosenses: "Ahora me alegro de padecer por vosotros, pues así voy completando en mi existencia mortal, y en favor del cuerpo de Cristo, que es la Iglesia, lo que aún falta al total de las tribulaciones cristianas" (Col 1, 24). Sobrino aplica esta consideración a los mártires, quienes, según dicho

20. I. Ellacuría, "El pueblo crucificado, ensayo de soteriología histórica", Revista Latinoamericana de Teología, 18 (1989), pp. 305-333, cfr. M. Maier, "Teología del pueblo crucificado. En el $70 .^{\circ}$ aniversario de Jon Sobrino", Revista Latinoamericana de Teología, 75 (2008), pp. 279-293.

21. J. Sobrino, Jesucristo liberador, óp. cit., pp. 440 y ss. 
versículo, completan en su propio cuerpo, de modo análogo, lo que aún falta de sufrimiento de Cristo.

Dentro del sentido salvífico de la muerte martirial, Ignacio Ellacuría distinguió el ámbito histórico-político del ámbito de la fe. Sin embargo, ambos tienen relación entre sí. ¿Qué sentido tendría la fe cristiana en la salvación si no se pudiera verificar de ninguna manera en la realidad histórica?

También el arzobispo Romero llegó a hablar en repetidas ocasiones del sentido soteriológico del sufrimiento:

Como pastor y como ciudadano salvadoreño, me apena profundamente el que se siga masacrando al sector organizado de nuestro pueblo solo por el hecho de salir ordenadamente a la calle para pedir justicia y libertad. Estoy seguro que tanta sangre derramada y tanto dolor causado a los familiares de tantas víctimas no serán en vano. Es sangre y dolor que regará y fecundará nuevas y cada vez más numerosas semillas de salvadoreños que tomarán conciencia de la responsabilidad que tienen de construir una sociedad más justa y humana, y que fructificará en la realización de las reformas estructurales audaces, urgentes y radicales que necesita nuestra patria. (Homilía del 27 de enero de 1980.)

En América Latina se actualiza de un modo nuevo la antigua comprensión del martirio como bautismo de sangre, como muerte con Cristo para resucitar en él. Los mártires están presentes como resucitados en la historia. Cuando se celebra una misa en recuerdo de los mártires, ello se expresa con el grito "ipresente!". Un poco antes de su asesinato, dijo Romero con profunda convicción: "Si me matan, resucitaré en el pueblo salvadoreño". Unas pocas semanas después del asesinato de sus compañeros de comunidad, escribió Sobrino en una reflexión muy personal:

Todos los mártires resucitan en la historia y cada uno a su manera. El caso de monseñor Romero es excepcional e irrepetible, pero también Rutilio Grande está presente en muchos campesinos, las religiosas norteamericanas siguen vivas en Chalatenango y La Libertad, Octavio Ortiz en El Despertar, y los cientos de campesinos martirizados en sus comunidades. ${ }^{22}$

\section{Conclusión}

Las reflexiones anteriores han mostrado con claridad que los mártires, además de ser una fuente de conocimiento teológico, son también una fuente ecuménica porque actualizan el Evangelio: ellos viven de manera ejemplar el seguimiento de Jesús hasta las últimas consecuencias de la entrega libre de la

22. J. Sobrino, "Compañeros de Jesús. El asesinato-martirio de los jesuitas salvadoreños", Revista Latinoamericana de Teología, 18 (1989), p. 301. 
vida por amor, en particular a los más pobres. Son un signo de los tiempos en el sentido de la definición de signos de los tiempos dada por Gaudium et spes: "los signos verdaderos de la presencia o de los planes de Dios" (GS 11). Los mártires actualizan la vida, cruz y resurrección de Jesús. Confrontan a la fe cristiana y a la teología con la urgencia del ser cristiano. Así, son un "locus theologicus", un lugar teológico, tal y como lo manifiesta Jon Sobrino: "En esos martirios, la realidad ha pronunciado una palabra última, no solo con cambios en la superficie de las cosas, sino con la vida y la muerte, el horror del pecado y la fascinación de la gracia" ${ }^{23}$.

Los mártires muestran que el pecado y la muerte son un hecho incuestionable de la vida. Son luz en el sentido de que alumbran la verdad de este mundo: este mundo es un mundo de víctimas. Sin embargo, muestran también que la gracia y la resurrección son una realidad de la historia. Los mártires llaman a la conversión y a la solidaridad. Evangelizan. El ejemplo más conocido es la huella que dejó Rutilio Grande en el arzobispo Romero. Los mártires abren nuevos espacios de vida. Indican que el amor y la solidaridad son una alternativa a la lógica dominante de la violencia y la opresión. Muestran que es posible vivir y morir en este mundo como ser humano y como Cristo. Ya no hay diferencias confesionales, sino que se trata del ser cristiano por antonomasia. Más aún, lo más ecuménico que hay es el martirio por amor. En la conocida metáfora de Tertuliano, la sangre de los mártires no solo es semilla para nuevos cristianos, sino también semilla para el ecumenismo.

23. J. Sobrino, "Los mártires jesuánicos", óp. cit., p. 246. 